Check for updates

Cite this: RSC Adv., 2017, 7, 17980

\section{Emission enhancement of GFP chromophore in aggregated state via combination of self-restricted effect and supramolecular host-guest complexation $\uparrow$}

\begin{abstract}
Shanshan Ge, Hongping Deng, ${ }^{*}$ Yue Su (D) and Xinyuan Zhu (D) *
The emission enhancement of GFP-like chromophores in the aggregated state is a great challenge due to its free conformational motions and aggregation-induced quenching (ACQ) features. Herein, the emission response of a GFP chromophore (GFPC) in its aggregated state has been greatly enhanced via combination of self-restricted effect and supramolecular host-guest complexation. Specifically, the benzene group of the GFP chromophore ( $\mathrm{HBHI}$ ) was tailored by 2,5-methoxy group to construct a self-restricted chromophore $(\mathrm{MBHI})$, which shows enhanced emission response in both solutions and aggregated state compared to $\mathrm{HBHI}$ due to the formation of the self-restricted effect. After conjugated to adamantine $(A D)$, the chromophore (MBIAD) exhibits aggregation-induced emission enhancement (AIEE) feature compared to $\mathrm{MBHI}$ in aggregated state. Moreover, the aggregated emission of MBIAD further enhances by complexation with proper $\beta$-cyclodextrin $(\beta-C D)$, which reduces strong $A C Q$ between chromophores. Furthermore, the aggregated emission can also be tuned by controlling the ratio of $\beta-C D$ and $A D$. Under a ratio of $1: 2$, MBIAD and Me- $\beta-C D$ can assemble into nanoparticle with a diameter of about $55 \mathrm{~nm}$, which has been applied to cell imaging due to the relatively low cell cytotoxicity.
\end{abstract}

Received 22nd January 2017 Accepted 9th March 2017

DOI: $10.1039 / \mathrm{c} 7 \mathrm{ra00974g}$

rsc.li/rsc-advances
The chromophore, 4-hydroxybenzylidene imidazolinone (HBI), formed in situ via autocatalytic dehydration/oxidation of a Ser-Tyr-Gly tripeptide, enables green fluorescent protein (GFP) eminent photophysical character, making it a powerful tool for fluorescence labeling in biology. ${ }^{19,20}$ Surprisingly, the fluorescence of either isolated or synthesized HBI diminishes dramatically by four orders of magnitude in fluid solvents due to an ultrafast internal conversion caused by free conformational motion around the CC bonds. ${ }^{21-24}$ Meanwhile, the solid power of HBI is also completely non-emissive because of the strong $\pi-\pi$ stacking between adjacent molecules. ${ }^{25-27}$ Over past years, the emission enhancement of HBI in fluid solutions has drawn great attention..$^{28}$ On the one hand, the fluorescence is recovered by physical encapsulation with supramolecular hosts, polymers, porous scaffolds, proteins or ribonucleic acid, which can inhibit the conformational free motion by forming a confined environment. ${ }^{29-32}$ On the other hand, chemical modification of the chromophore has also been applied to enhance the fluorescence emission. An effective strategy is to develop conformational locked chromophores via chemically locking strategy, which greatly suppresses the chromophores' free torsional rotations and results in highly luminescent chromophores. $^{33,34}$ Recently, our research group has constructed a family of unlocked self-restricted GFP chromophore analogues with dramatic emission enhancement in fluid solutions. ${ }^{35}$ Considering the non-emissive and ACQ nature of HBI, it
School of Chemistry and Chemical Engineering, State Key Laboratory of Metal Matrix Composites, Shanghai Jiao Tong University, 800 Dongchuan Road, Shanghai 200240, P. R. China. E-mail: happy321@sjtu.edu.cn; xyzhu@sjtu.edu.cn; Fax: +86-2154741297

$\dagger$ Electronic supplementary information (ESI) available. See DOI: 10.1039/c7ra00974g 
is a great challenge to enhance its emission response in aggregated state in solutions.

Cyclodextrins (CDs) are characteristic of a hydrophilic exterior surface and a hydrophobic interior cavity, which can accommodate a wide range of molecules as guests. Among the varieties of such host-guest pairs, the inclusion complex of $\beta$-CD and adamantly group (AD) has been mostly investigated due to their high association constant. ${ }^{36}$ This host-guest interaction has been greatly employed to build supramolecular assemblies. ${ }^{37}$ Given the flexibility of supramolecular chemistry, host-guest interaction turns out to be an effective approach to tune the optical properties of fluorescent polymers or dyes. ${ }^{\mathbf{3 8 - 4 0}}$ We tried to learn from previous reports of emission enhancement by alkyl substituent-mediated crystal packing and artificially engineered porous scaffolds, which inspires us to investigate the possibility of enhancing the emission of HBI in aggregated state via combination of self-restricted effect and supramolecular host-guest complexation. ${ }^{30,41}$ Hopefully, the dual function would greatly enhance the fluorescence of HBI in its aggregated state.

Herein, we report the emission enhancement of HBI in the aggregated state via the combination of self-restricted effect and host-guest complexation. By $2+3$ cycloaddition, the selfrestricted chromophore (MBHI) was constructed, which shows enhanced emission response in both solutions and aggregated state compared to the GFP chromophore (HBHI) due to selfrestricted effect. After conjugated with adamantine (AD), the chromophore (MBIAD) exhibits some aggregation-induced emission enhancement (AIEE) feature compared to that of $\mathrm{MBHI}$ in the aggregated state. Moreover, the aggregated emission of MBIAD further increases after complexation with proper $\beta$-CD due to its isolation effect, which can reduce strong $\pi-\pi$ interaction between chromophores. By controlling the amount of $\beta-\mathrm{CD}$, the emission of the assembled complex can also be tuned. As a demonstration, the emission enhanced chromophores have been applied to cell imaging, providing another effective approach for the application of GFPc analogue in aggregated state (Fig. 1).

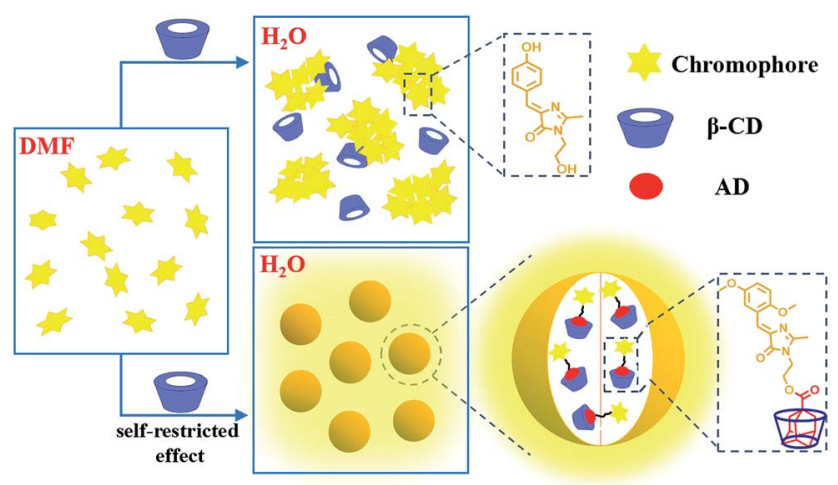

Fig. 1 Concept of emission enhancement of GFP chromophore in aggregated state. Upper: the aggregated emission of GFP chromophore $(\mathrm{HBIHI})$ is very dim due to free conformational motion and $A C Q$; below: the aggregated emission is greatly enhanced via self-restricted effect and host-guest interaction.

\section{Experimental section}

\subsection{Materials and chemicals}

2,5-Dimethoxybenzaldehyde, 2-aminoethanol, $\beta$-cyclodextrin ( $\beta$ $\mathrm{CD}$ ), methyl- $\beta$-cyclodextrin (Me- $\beta$-CD), triacetyl- $\beta$-cyclodextrin (Ac$\beta$-CD), 1-adamantanecarboxylic acid, $N$-(4-pyridyl)dimethylamine (DMAP), $N, N^{\prime}$-dicyclohexylcarbodiimide (DCC) were purchased and used as received. Dichloromethane was dried over $\mathrm{CaH}_{2}$ and refluxed for $2 \mathrm{~h}$ before use. Ethanol was refluxed over calcium oxide for $3 \mathrm{~h}$ before use. Methyl 2-(1-ethoxy-ethylideneamino) acetate (MEEA) and 4-(4-hydroxy-benzylidene)-1-hydroxyethyl-2methyl-5-imidazolinone (HBHI) were synthesized as detailed by our previous publications..$^{292}$ All other reagents and solvents were purchased commercially and used without further purification. For cell experiments, MCF-7 cells (a human breast adenocarcinoma cell line) were purchased from ATCC. DMEM (Dulbecco's modified Eagle's medium), FBS (fetal bovine serum), antibiotics (50 units per $\mathrm{mL}$ penicillin and 50 units per $\mathrm{mL}$ streptomycin) were all purchased from ThermoFisher.

\subsection{Characterizations}

Both ${ }^{1} \mathrm{H}$ and ${ }^{13} \mathrm{C}$ NMR spectra were measured with Varian MERCURY plus-400 spectrometer at $400 \mathrm{MHz}$ and $100 \mathrm{MHz}$ instruments respectively using dimethylsulfoxide- $d_{6}$ (DMSO- $d_{6}$ ) or chloroform- $d\left(\mathrm{CDCl}_{3}-d\right)$ as the solvent at $298 \mathrm{~K}$. Chemical shifts $(\delta)$ are quoted in parts per million (ppm) and coupling constants $(J)$ are recorded in hertz $(\mathrm{Hz})$. The chemical shifts were referenced to the residual peak of deuterated solvent: DMSO- $d_{6}(2.48 \mathrm{ppm})$; $\mathrm{CDCl}_{3}$ (7.26 ppm). FTIR spectra were tested with a Perkin Elmer Paragon 1000 spectrophotometer between 4000 and $450 \mathrm{~cm}^{-1}$. All sample slices were measured by pestling the solid sample with dry potassium bromide $(\mathrm{KBr})$ and then moulding under high pressure. HRMS was measured on a Waters Micromass Q-TOF Premier Mass Spectrometer with data acquired for each sample from 50 to 1000 Da with a $0.10 \mathrm{~s}$ scan time and a $0.01 \mathrm{~s}$ interscan delay over a $10 \mathrm{~min}$ analysis time. The UV-Vis absorption spectra of the sample solutions were tested at room temperature on a Perkin Elmer Lambda 20 UV-Vis spectrometer with a scan speed of $480 \mathrm{~nm} \mathrm{~min}^{-1}$. The fluorescence emission spectra were measured with a PTI-QM/TM/IM steady-state \& time-resolved fluorescence spectrofluorometer (USA/CAN Photon Technology International Int.). Excitation wavelength was the maximum UVVis absorption wavelength. Dynamic light scattering (DLS) measurements were carried out on a Malvern Zetasizer Nano ZS90 apparatus equipped with a $4.0 \mathrm{~mW} \mathrm{He}-\mathrm{Ne}$ laser operating at $\lambda=633 \mathrm{~nm}$. All samples were measured at room temperature with a scattering angle of $90^{\circ}$. Transmission Electron Microscopy (TEM) studies were performed with a JEOL JEM-100CX-II instrument at a voltage of $200 \mathrm{kV}$. Samples were prepared by drop-casting complex solutions onto carbon-coated copper grids and then air-drying at room temperature before measurement.

\subsection{Synthesis}

General procedure for synthesis of GFPc analogue. GFPc analogue was conveniently synthesized through a 1,3-dipolar, [2 +3 ] cycloaddition of an imide with aromatic Schiff bases as 
reported by Deng. ${ }^{29}$ Briefly, Schiff bases were prepared by combining the given aromatic aldehyde $(1 \mathrm{mmol})$ with ethanolamine $(1.1 \mathrm{mmol})$ in ethanol for $12 \mathrm{~h}$ at room temperature. Then, the solvent was removed under vacuum and methyl 2-(1ethoxyethylideneamino)acetate $(1.1 \mathrm{mmol})$ was added in ethanol. The reaction was allowed to stir overnight under ambient conditions. The progression of the reaction was monitored by thin-layer-chromatography. Finally, the mixture was purified by silica gel column chromatography using ethyl acetate and petroleum ether as the solvents.

Synthesis of 4-(2,5-dimethoxylbenzylidene)-1-hydroxyethyl-2methyl-5-imidazolinone (MBHI). 2,5-Dimethoxybenzaldehyde was stirred with 2-aminoethanol in ethanol in a molar ratio of $1: 1.1$ to get the Schiff bases, which then reacted with methyl 2(1-ethoxy-ethylideneamino)acetate (MEEA) to obtain the crude products. Products were purified by silica gel column chromatography and characterized by ${ }^{1} \mathrm{H}$ and ${ }^{13} \mathrm{C}$ NMR, HRMS, and IR spectra. Yellow solid, yield $72 \% .{ }^{1} \mathrm{H}$ NMR (400 MHz, DMSO- $\left.d_{6}\right)$ : $\delta 8.38(\mathrm{t}, J=1.7 \mathrm{~Hz}, 1 \mathrm{H}), 6.98(\mathrm{~d}, J=1.7 \mathrm{~Hz}, 2 \mathrm{H}), 4.94(\mathrm{~d}, J=$ $5.5 \mathrm{~Hz}, 1 \mathrm{H}), 3.81(\mathrm{~s}, 4 \mathrm{H}), 3.73-3.71(\mathrm{~m}, 4 \mathrm{H}), 3.60(\mathrm{t}, J=5.4 \mathrm{~Hz}$, $2 \mathrm{H}), 3.51(\mathrm{t}, J=5.4 \mathrm{~Hz}, 2 \mathrm{H}), 3.31(\mathrm{~s}, 1 \mathrm{H}), 2.48(\mathrm{dt}, J=3.6,1.8 \mathrm{~Hz}$, $1 \mathrm{H}), 2.37(\mathrm{~s}, 3 \mathrm{H}) .{ }^{13} \mathrm{C}$ NMR (100 MHz, DMSO- $\left.d_{6}\right): \delta$ 170.61, 165.25, 153.66, 153.57, 139.15, 123.62, 118.01, 117.71, 117.65, 112.90, 59.46, 56.82, 56.09, 43.61, 16.49. HRMS: $\mathrm{m} / z$ calculated for $\left[\mathrm{C}_{15} \mathrm{H}_{19} \mathrm{~N}_{2} \mathrm{O}_{4}\right]^{+}$: 291.1267, found: 291.1332. IR (KBr): 3442, 3087, 2953, 2824, 1691, 1635, 1499, 1405, 1240, 1048, 804, 692, $596 \mathrm{~cm}^{-1}$.

Synthesis of 2-(4-(2,5-dimethoxylbenzylidene)-2-methyl-5imidazolinone)ethyl adamantane-1-carboxylate (MBIAD). A mixture of 4-(2,5-dimethoxylbenzylidene)-1-hydroxyethyl-2methyl-5-imidazolinone (MBHI), 1-adamantanecarboxylic acid, $N$-(4-pyridyl)dimethylamine (DMAP), and $N, N^{\prime}$-dicyclohexylcarbodiimide (DCC) were stirred in $5 \mathrm{~mL}$ DCM for $12 \mathrm{~h}$. The mixture was purified by silica gel column chromatography using acetate and petroleum ether as the solvents. Yellow solid, yield 41\%. ${ }^{1} \mathrm{H}$ NMR (400 MHz, $\left.\mathrm{CDCl}_{3}\right): \delta 8.38(\mathrm{~d}, J=3.1 \mathrm{~Hz}, 1 \mathrm{H})$, 7.65 (s, 1H), 6.93 (dd, $J=9.0,3.1 \mathrm{~Hz}, 1 \mathrm{H}), 6.83(\mathrm{~d}, J=9.0 \mathrm{~Hz}$, $1 \mathrm{H}), 4.24(\mathrm{~s}, 2 \mathrm{H}), 3.88(\mathrm{t}, J=5.6 \mathrm{~Hz}, 2 \mathrm{H}), 3.84(\mathrm{~s}, 6 \mathrm{H}), 2.45(\mathrm{~s}$, $3 \mathrm{H}), 2.00(\mathrm{~s}, 3 \mathrm{H}), 1.85(\mathrm{~d}, J=2.7 \mathrm{~Hz}, 6 \mathrm{H}), 1.69(\mathrm{~d}, J=7.9 \mathrm{~Hz}, 6 \mathrm{H})$. ${ }^{13} \mathrm{C}$ NMR (100 MHz, $\left.\mathrm{CDCl}_{3}\right): \delta 177.67,170.67,161.54,154.15$, 153.67, 138.92, 138.12, 123.87, 121.76, 118.19, 117.29, 112.04, 61.84, 56.42, 56.01, 39.83, 39.01, 36.60, 28.04, 16.07. HRMS: $\mathrm{m} / \mathrm{z}$ calculated for $\left[\mathrm{C}_{26} \mathrm{H}_{33} \mathrm{~N}_{2} \mathrm{O}_{5}\right]^{+}$: 453.2311, found: 453.2375. IR (KBr): 3431, 2905, 1713, 1636, 1411, 1227, 1073, 834, $690 \mathrm{~cm}^{-1}$.

\subsection{Cell experiments}

Cell culture and imaging. MCF-7 cells (a human breast adenocarcinoma cell line) were seeded in flexiPERM reusable cell culture chambers in combination of glass coverslips and cultured in DMEM (Dulbecco's modified Eagle's medium) supplied with 10\% FBS (fetal bovine serum) and antibiotics (50 units per $\mathrm{mL}$ penicillin and 50 units per $\mathrm{mL}$ streptomycin) at $37{ }^{\circ} \mathrm{C}$ under a humidified atmosphere containing $5 \% \mathrm{CO}_{2}$. After $24 \mathrm{~h}$ of culture, the self-assembled complexes were added to the culture wells, and the cells were incubated at $37{ }^{\circ} \mathrm{C}$ for $30 \mathrm{~min}$. After washing with PBS three times, the cells were fixed with $4 \%$ formaldehyde for $15 \mathrm{~min}$ at room temperature, and then the slides were mounted and observed using a Leica DMI6000B. The excitation wavelength for all samples was $405 \mathrm{~nm}$.

Cytotoxicity measurements. The cytotoxicity of the complex was determined using an MTT viability assay against MCF-7 cells. Firstly, MCF-7 cells were placed into 96-well plates at a density of $1 \times 10^{4}$ cells per well in $200 \mu \mathrm{L}$ medium. After $24 \mathrm{~h}$, the culture medium was replaced with $200 \mu \mathrm{L}$ of serial dilutions of aggregates. The cells were cultured for another $48 \mathrm{~h}$. Then, 20 $\mu \mathrm{L}$ of $5 \mathrm{mg} \mathrm{mL}{ }^{-1}$ MTT assay stock solution in PBS was added to each well. After $4 \mathrm{~h}$, the medium was replaced with $200 \mu \mathrm{L}$ of DMSO, and the absorbance was measured using a BioTek Synergy $\mathrm{H} 4$ at a wavelength of $490 \mathrm{~nm}$.

\section{Results and discussion}

\subsection{Synthesis of chromophores}

Conveniently, all chromophores were prepared by a $2+3$ cycloaddition method with high yields. Through an esterification reaction, $\mathrm{AD}$ was covalently linked to $\mathrm{MBHI}$ to obtain MBIAD. Firstly, HBHI was designed and synthesized as a model compound of GFP core chromophore HBI, which further serves as a control for MBHI and MBIAD. To construct the selfrestricted chromophore, the benzene ring of $\mathrm{HBHI}$ was tailored by 2,5-methoxy group to get MBHI. The molecular structures of HBHI, MBHI and MBIAD are given in scheme 1.

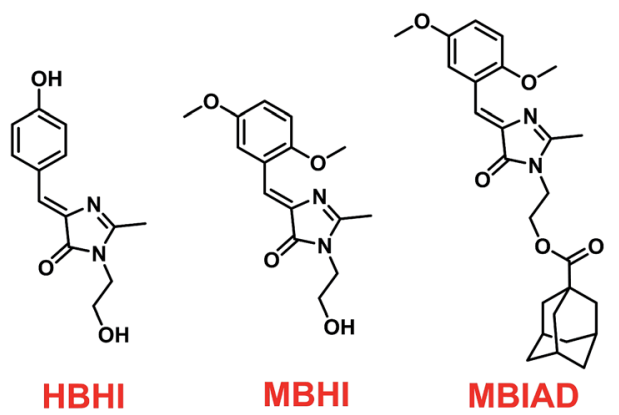

Scheme 1 The molecular structures of $\mathrm{HBHI}, \mathrm{MBHI}$ and MBIAD. $\mathrm{HBHI}$ is used as a model compound for the GFP core chromophore.

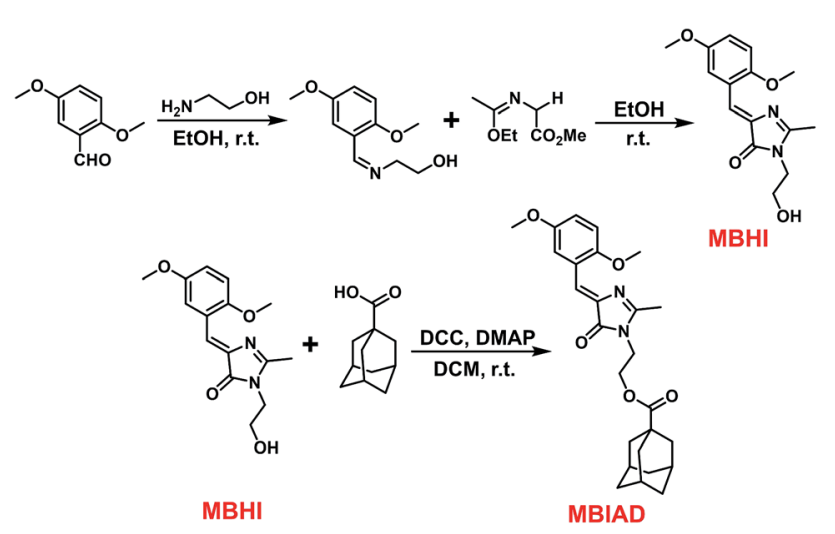

Scheme 2 The synthetic routes for $M B H I$ and MBIAD, which involve a $2+3$ cycloaddition followed by another esterification reaction. 
Synthetic procedures are shown in Scheme 2 and details of characterizations are given in the Experimental section.

\subsection{Optical properties in fluid solutions}

As shown in Fig. 2, the common optical properties of synthesized chromophores were tested in ethyl acetate (EA). For HBHI, the absorption peak is at around $368 \mathrm{~nm}$, which redshifts to $392 \mathrm{~nm}$ in the case of MBHI due to the formation of the selfrestricted effect. And, the absorption shows little change after conjugating to $\mathrm{AD}$ (MBIAD). However, with the same concentration, $\mathrm{HBHI}$ is almost non-emissive in EA; while self-restricted MBHI is highly emissive with an emission peak at about $475 \mathrm{~nm}$, which is in agreement with reported results. ${ }^{35}$ After conjugating to $\mathrm{AD}$, the emission enhances by 1.2-fold at the same concentration, which might be ascribed to the reduced hydrogen bonding effect for MBHI.

Subsequently, the solvent dependence of absorption and emission were readily recorded in both aprotic and protic solvents. As shown in Fig. 4A, MBIAD shows an intense absorption peak at $392 \mathrm{~nm}$ in Hex. In aprotic solvents, the absorption spectrum and peak hardly changes from Hex to ACN. In $\mathrm{MeOH}$, the absorption peak redshifts about $398 \mathrm{~nm}$ and the secondary absorption peak at about $347 \mathrm{~nm}$ strengthens due to the influence of solvent-solute hydrogen bonding. ${ }^{43}$ Generally, the absorption of MBIAD shows little dependent on solvent polarity, which obeys the same rule for that of MBHI and $\mathrm{HBHI}$ (Fig. 3A and S8 $\dagger$ ). However, the absorption peak of HBHI blueshifts to around $370 \mathrm{~nm}$ and hydrogen bonding effect has a small influence on MBHI and little influence on HBHI. Meanwhile, as shown in Fig. 4B, the emission of MBIAD displays a single peak at about $445 \mathrm{~nm}$ in Hex. Upon going from Hex to $\mathrm{MeOH}$, the fluorescence emission peak exhibits an obvious red shift of about $100 \mathrm{~nm}$ from $445 \mathrm{~nm}$ to $542 \mathrm{~nm}$, showing a remarkable solvatofluorochromism feature. ${ }^{35}$ The emission peak further redshifts in $\mathrm{MeOH}$ due to strong solventsolute hydrogen bonding. ${ }^{43}$ In the case of MBHI, obvious solvatofluorochromism feature is also observed with the increasing of solvent polarity from Hex to $\mathrm{MeOH}$ (Fig. 3B).

\subsection{Fluorescent property in aggregated state}

To investigate the fluorescent property in aggregated state, the emission spectra of these three chromophores were measured
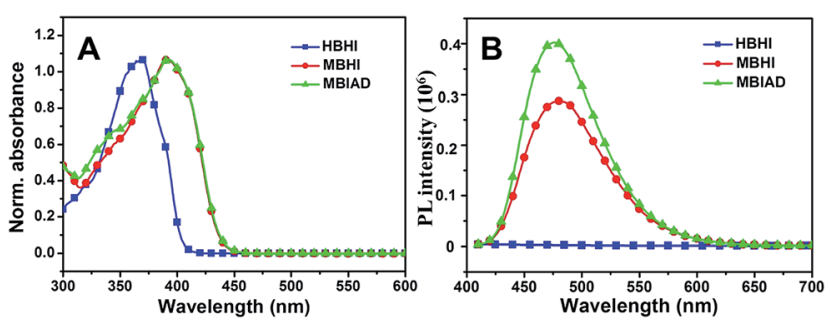

Fig. 2 The normalized UV-Vis absorption (A) and fluorescence emission spectra (B) of $\mathrm{HBHI}, \mathrm{MBHI}$ and MBIAD in ethyl acetate (EA). The excitation wavelength was the corresponding absorption maximum.
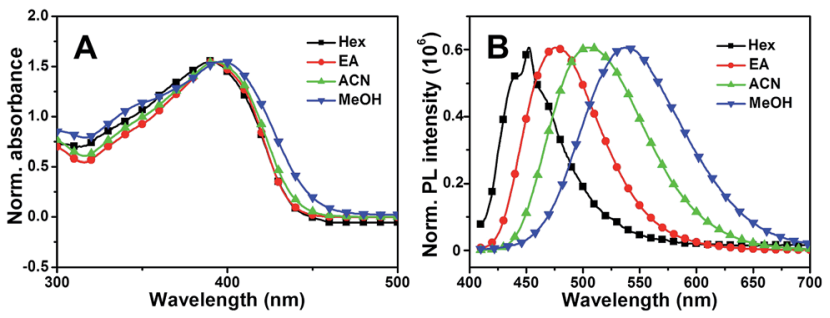

Fig. 3 The normalized UV-Vis absorption (A) and fluorescence emission spectra (B) of $\mathrm{MBHI}$ in various solvents from $\mathrm{Hex}$ to $\mathrm{MeOH}$. The excitation wavelength was the corresponding absorption maximum.
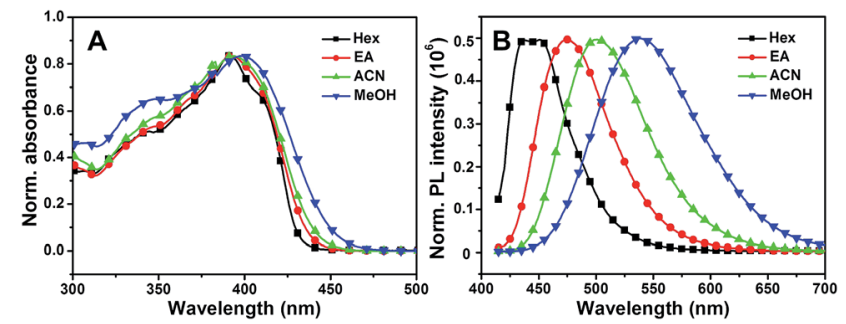

Fig. 4 The normalized UV-Vis absorption (A) and fluorescence emission spectra (B) of MBIAD in various solvents from Hex to $\mathrm{MeOH}$. The excitation wavelength was the corresponding absorption maximum.

in mixed solvents of DMF (a good solvent) and water (a poor solvent).

As shown in Fig. 5A, HBHI is weakly emissive in DMF, which shows two-orders of magnitude reduction compared to that of MBHI and MBIAD. With the increasing of water content in the mixed solvent, the emission further decreases due to strong $\pi-$ $\pi$ interaction..$^{25}$ In the case of MBHI, as shown in Fig. 5B, obvious fluorescence with an emission peak at $478 \mathrm{~nm}$ is observed in DMF. With the increasing of water content, the fluorescence quenched heavily accompanied by large red shifts to $540 \mathrm{~nm}$ due to strong hydrogen bonding and $\pi-\pi$ interaction in aggregated state. This phenomenon agrees well with the typical aggregation-caused quenching mechanism. ${ }^{\mathbf{4}}$ For MBIAD, with the increasing of water content, the emission intensity decreases below $80 \%$ water content, which follows the same reason of strong solvent-solute H-bonding and $\pi-\pi$ interaction; but enhances 4 -fold in the cases of higher water contents with obvious blue-shift of about $47 \mathrm{~nm}$ (Fig. 5D), showing typical aggregation-induced emission enhancement phenomenon. ${ }^{13}$ The enhanced emission can be ascribed to the extrusion of water from the aggregates and the segregation effect of $\mathrm{AD}$ in the compact aggregated state, which reduces the strong H-bonding and $\pi-\pi$ interaction greatly.

To further enhance the fluorescence emission in aggregated state, the effect of host-guest complexation between $\mathrm{CD}$ and $\mathrm{AD}$ is investigated. As depicted in Fig. 6A, HBHI is almost nonemissive. Under the same condition, the great enhancement of emission for MBHI is due to the influence of self-restricted effect and the further emission increase of MBIAD is owing to 

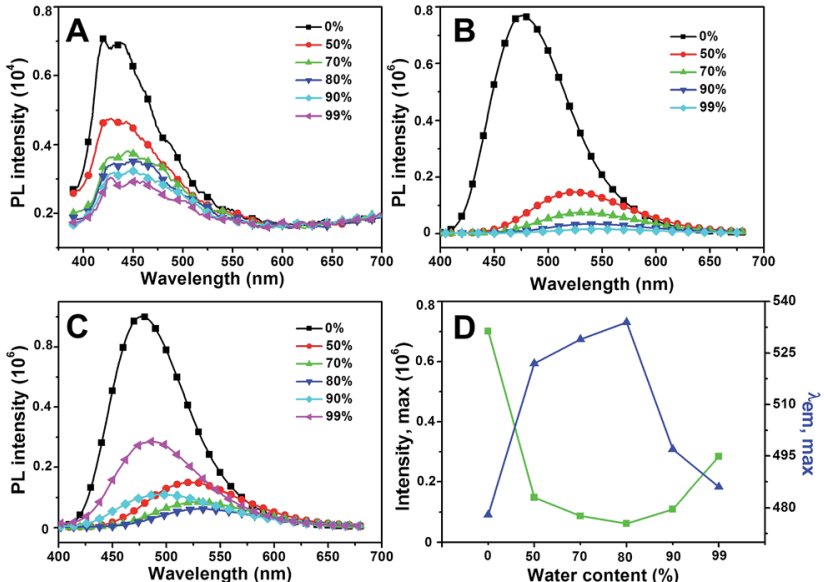

Fig. 5 The emission of (A) HBHI, (B) MBHI and (C) MBIAD in DMF/ $\mathrm{H}_{2} \mathrm{O}$ mixed solvents. Water contents are given. (D) The fluorescence intensity and peak maximum changes with the increasing of water contents for MBIAD in (C). Concentration $=50 \mu \mathrm{M}, \lambda_{\mathrm{ex}}=400 \mathrm{~nm}$. Slits: $2.4 / 2.4 \mathrm{~nm}$.

the segregation effect of $\mathrm{AD}$ in aggregated state. Actually, the emission in Fig. 6A serves as control experiments for the corresponding results with different kinds of CDs. As shown in Fig. 6, the fluorescence is very $\operatorname{dim}$ for $\mathrm{HBHI}$ in all cases due to the non-emissive nature and strong internal molecular interactions. ${ }^{45}$ Meanwhile, the emission intensity of MBHI hardly changes regardless of the addition of different kinds of CDs. MBHI can't interact with CD through host-guest complexation from the result of ${ }^{1} \mathrm{H}$ NMR tests (Fig. S9†), which has little influence on the self-aggregating process of $\mathrm{MBHI}$ molecules. For MBIAD, the complexation with $\beta$-CD enhances the emission by 1.5 -fold compared to $\mathrm{MBHI}$, which is due to the segregation effect of $\beta$-CD in the aggregated state caused via the host-guest
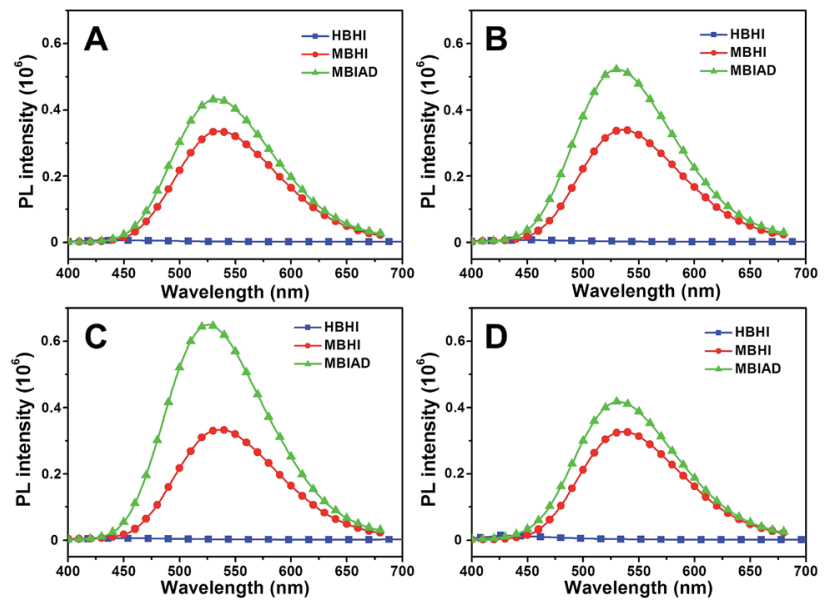

Fig. 6 Water was added dropwise to GFPc/cyclodextrin mixed solution. The emission spectra of $\mathrm{HBHI}, \mathrm{MBHI}$ and $\mathrm{MBIAD}$ in aggregated state after complexation with different CDs: $(A)$ without $C D$, control; (B) $\beta$-CD; (C) Me- $\beta-C D$; (D) Ac- $\beta$-CD. Water content is about $85 \%$ for all samples. Concentration (chromophore) $=50 \mu \mathrm{M}$, concentration $(C D)=100 \mu \mathrm{M}$. Slits: $3.2 / 3.2 \mathrm{~nm}$. interaction. Moreover, the complexation with Me- $\beta$-CD further enhances the emission by 2.0 -fold because the hydrophobic effect of Me- $\beta$-CD can better isolate the chromophore and inhibit its free conformational motion. ${ }^{46}$ However, the emission is hardly affected in the case of Ac- $\beta$-CD due to the big steric hindrance of the acetyl group which hinders the complexation between $\mathrm{AD}$ and $\mathrm{CD}$.

To make it clearer, the emission spectra of different chromophores with varied CDs were overlapped in Fig. 7. In all cases, the model compound of GFP chromophore, HBHI, is completely non-emissive. For MBHI, the aggregated emission enhances greatly compared to that of HBHI due to the selfrestricted effect. ${ }^{35}$ However, the addition of different CDs hardly affects its emission response because the aggregated process can't be disturbed due to the lack of interactions between MBHI and CDs. In the case of MBIAD, the aggregated emission further enhances compared to that of MBHI owing to the segregation effect of $\mathrm{AD}$ group to the bulk chromophores. And, the complexation with $\beta$-CD further increases the emission intensity due to the better segregation effect of CD compared to that of $\mathrm{AD} .{ }^{46}$ Meanwhile, the complexation with Me- $\beta$-CD results in the maximum emission intensity due to the hydrophobic nature of Me- $\beta$-CD. But, the addition of Ac- $\beta$-CD shows little influence compared to MBIAD control because the large steric hindrance of the acetyl group inhibits the complexation between $\mathrm{AD}$ and $\mathrm{CD}$. Importantly, the aggregated emission enhances more than 100-fold for MBIAD-Me- $\beta$-CD complex compared to that of the GFP chromophore HBHI. Through the above results, the self-restricted effect and host-guest complexation between $\mathrm{AD}$ and $\mathrm{CD}$ are essential for the emission enhancement in aggregated state.

\subsection{Tuning of aggregated emission}

Typically, intermolecular interactions such as hydrogen bonding can also act as driving force to construct complexes. ${ }^{47}$ As shown in Fig. 8A, the aggregated emission of MBIAD in complexation with different molar ratio of Me- $\beta$-CD was further investigated. With the increase of Me- $\beta$-CD from 0 to 1 eq., the aggregated emission enhances gradually due to the increase of

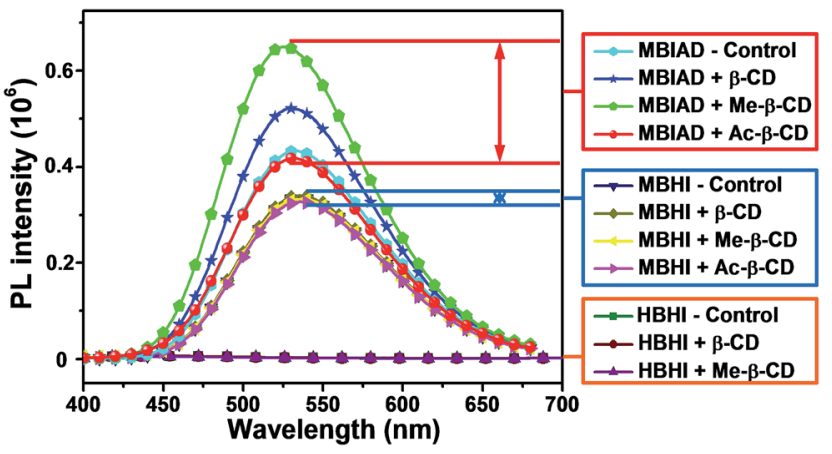

Fig. 7 Comparison of the emission performance of different chromophores in aggregated state with or without different CDs. Water content is $85 \%$, concentration (chromophore) $=50 \mu \mathrm{M}$, concentration (cyclodextrin) $=100 \mu \mathrm{M}$. Slits: $3.2 / 3.2 \mathrm{~nm}$. 

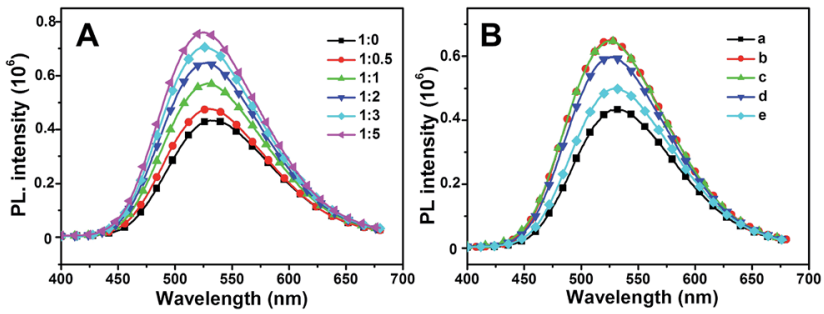

Fig. 8 (A) The emission spectra of MBIAD/Me- $\beta-C D$ complex with different molar ratio of MBIAD and Me- $\beta-C D$ ranging from $1: 0$ to $1: 5$. Water content is $85 \%$, concentration $(\mathrm{MBIAD})=50 \mu \mathrm{M}$. Slits: 3.21 $3.2 \mathrm{~nm}$. (B) The emission spectra of MBIAD/Me- $\beta$-CD complex with different molar ratio of additional $A D$ : (a) MBIAD, no CD, no $A D$; (b) $n(\mathrm{MBIAD}): n(\mathrm{CD})=1: 2$, no $\mathrm{AD}$; (c) $n(\mathrm{MBIAD}): n(\mathrm{CD}): n(\mathrm{AD})=$ $1: 2: 1 ; \quad$ (d) $n(\mathrm{MBIAD}): n(\mathrm{CD}): n(\mathrm{AD})=1: 2: 2 ; \quad$ (e) $n(\mathrm{MBIAD}): n(\mathrm{CD}): n(\mathrm{AD})=1: 2: 5$. Water content is $85 \%$, concentration $(M B I A D)=50 \mu \mathrm{M}$. Slits: $3.2 / 3.2 \mathrm{~nm}$.

complexation between $\mathrm{AD}$ and $\mathrm{CD}$. After further increase of the ratio of Me- $\beta$-CD, the aggregated emission still enhances gradually (from $1: 1$ to $1: 5$ ). It is generally reported that $\mathrm{AD}$ and $\mathrm{CD}$ can form complexation in a $1: 1$ molar ratio. ${ }^{48}$ Under higher molar ratio, the additional $\mathrm{CD}$ can further segregated the chromophore via molecular interactions with MBIAD-Me- $\beta$-CD complex, which will decrease $\pi-\pi$ stacking, resulting in the further enhancement of fluorescence emission. ${ }^{49}$ Meanwhile, the fluorescence emission can also be tuned by adding different amounts of AD. As shown in Fig. 8B, the fluorescence emission decreases with the increasing of $\mathrm{AD}$ due to the competitive complexation of $\mathrm{AD}$ and MBIAD with CD. Definitely, the
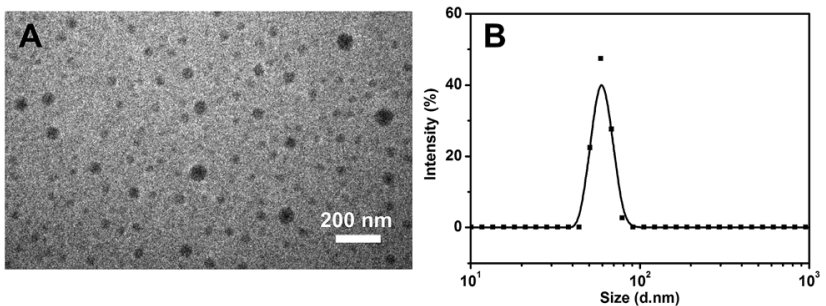

Fig. 9 The TEM image (A) and DLS measurement (B) of the assembled complex of Me- $\beta-C D / M B I A D$ with a $2: 1$ molar ratio. The PDI of DLS result is 0.407 .

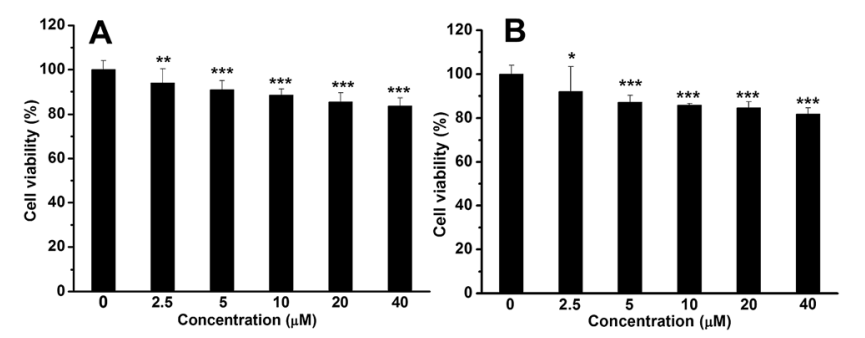

Fig. 10 Cell viability of MCF-7 cells treated with different concentrations of MBIAD-Me- $\beta$-CD complex (A) $n(\mathrm{MBIAD}): n(\mathrm{Me}-\beta-\mathrm{CD})=1: 1$; (B) $n(\mathrm{MBIAD}): n(\mathrm{Me}-\beta-\mathrm{CD})=1: 2$ after cultured for 24 h. $P^{*}<0.5, P^{* *}$ $<0.01, P^{* * *}<0.001$

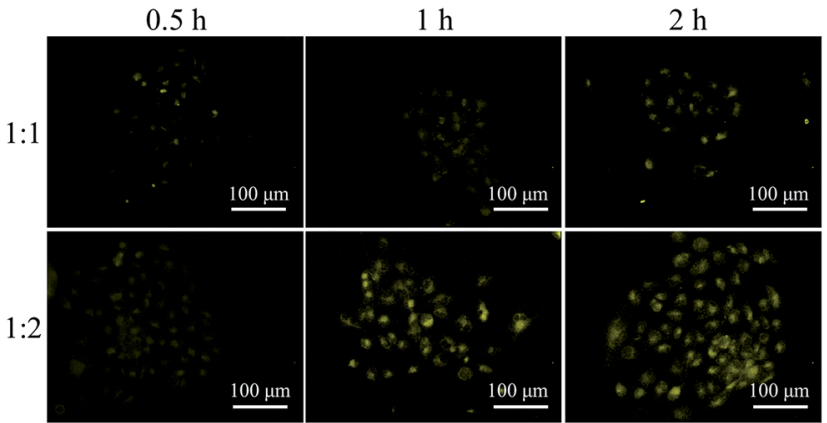

Fig. 11 Fluorescent MBIAD/Me- $\beta-C D$ complex (mole rate: $1: 2$ ) for fluorescence imaging of MCF-7 cells after different incubation time. Concentration $=10 \mu \mathrm{M}, \lambda_{\text {ex }}=405 \mathrm{~nm}$.

supramolecular host-guest complexation turns out to be a fabulous method to tune the emission response of GFP chromophore in aggregated state.

\subsection{Cell imaging}

GFP has been widely used for cell imaging or tracking in biology. ${ }^{20}$ To study the possibility for cell imaging, the morphology of the assembled complex between Me- $\beta-\mathrm{CD} /$ MBIAD with a $2: 1$ molar ratio was firstly investigated using both TEM and DLS tests. As shown in Fig. 9, the assembled complex can form a sphere nanoparticle with a diameter of around $55 \mathrm{~nm}$ from both results. Considering the enhanced emission of MBIAD in aggregated state, the potential application in cell imaging was also further studied. The cytotoxicity of MBIAD-Me- $\beta$-CD complex was evaluated by MTT assay using MCF-7 cells. As shown in Fig. 10A and B, the cell viability of MCF-7 cells treated with different mole ratios and concentrations of the assembled complex demonstrate little cytotoxicity even when the concentration is up to $40 \mu \mathrm{M}$ after co-cultured for 24 hours. Thus, the MBIAD-Me- $\beta$-CD complex can be further applied to cell imaging. As shown in Fig. 11, both complexes with a $1: 1$ and $1: 2$ molar ratio can enter into the MCF-7 cells with yellow fluorescent signals, which enhance gradually with increasing time. However, stronger yellow fluorescence with the complex of $1: 2$ ratio can be observed under the same condition, demonstrating the ability of MBIAD-Me- $\beta$-CD complex for cell imaging application.

\section{Conclusions}

In conclusion, the emission enhancement of the GFP chromophore in aggregated state has been greatly enhanced via combination of self-restricted effect and supramolecular hostguest complexation due to the inhibition of molecular motion and the reduction of $\pi-\pi$ interaction. With the influence of supramolecular host-guest complexation, physically molecular interactions can also further enhance the aggregated emission response. Moreover, the aggregated emission can be easily tuned by changing the co-assembly constituents of $\mathrm{CD}, \mathrm{AD}$ and MBIAD. Due to the enhanced emission and low cytotoxicity, the chromophore-based host-guest complex can be applied to cell 
imaging, raising the possibility toward chemical and biological applications using nanoaggregates derived from GFP-like fluorophores.

\section{Acknowledgements}

We are grateful to the financial support from National Basic Research Program of China (2015CB931801), National Key Research and Development Plan of China (2016YFA0201500), and National Natural Science Foundation of China (51473093).

\section{Notes and references}

1 U. Panda, S. Roy, D. Mallick, P. Dalapati, S. Biswas, N. B. Manik, A. Bhattacharyya and C. Sinha, J. Lumin., 2016, 175, 44-49.

2 J. Huang, N. Sun, Y. Q. Dong, R. L. Tang, P. Lu, P. Cai, Q. Q. Li, D. G. Ma, J. G. Qin and Z. Li, Adv. Funct. Mater., 2013, 23, 2329-2337.

3 S. Ast, T. Schwarze, H. Mller, T. Kçrzdçrfer, A. Drkop and H. J. Holdt, Chem.-Eur. J., 2013, 19, 14911-14917.

4 J. Qian, Z. F. Zhu, A. J. Qin, W. Qin, L. L. Chu, F. H. Cai, H. Q. Zhang, Q. Wu, R. R. Hu, B. Z. Tang and S. L. He, Adv. Mater., 2015, 27, 2332-2339.

5 M. M. Zheng, Y. Q. Wang, H. Shi, Y. X. Hu, L. D. Feng, Z. L. Luo, M. Zhou, J. He, Z. Y. Zhou, Y. Zhang and D. J. Ye, ACS Nano, 2016, 10, 10075-10085.

6 P. Bandyopadhyay and A. K. Ghosh, J. Phys. Chem. B, 2009, 113, 13462-13464.

7 S. Yoo, J. H. Lee, B. H. Sohn, I. Eom, T. Joo, S. J. An and G. C. Yi, Adv. Funct. Mater., 2008, 18, 2984-2989.

8 W. B. Li, J. N. Zhang, Y. Zhou and P. Zhang, Chem. Commun., 2011, 47, 5834-5836.

9 S. Basak, N. Nandi, A. Baral and A. Banerjee, Chem. Commun., 2015, 51, 780-783.

10 V. Lau and B. Heyne, Chem. Commun., 2010, 46, 3595-3597.

11 J. Dong, K. M. Solntsev and L. M. Tolbert, J. Am. Chem. Soc., 2009, 131, 662-670.

12 H. Zhou, J. S. Li, M. H. Chua, H. Yan, Q. Ye, J. Song, T. T. Lin, B. T. Zhong and J. W. Xu, Chem. Commun., 2016, 52, 1247812481.

13 J. Luo, Z. Xie, J. W. Y. Lam, L. Cheng, H. Chen, C. Qiu, H. S. Hwok, X. Zhan, Y. Liu, D. Zhu and B. Z. Tang, Chem. Commun., 2001, 18, 1740-1741.

14 H. B. Shi, J. Z. Liu, J. L. Geng, B. Z. Tang and B. Liu, J. Am. Chem. Soc., 2012, 134, 9569-9572.

15 C. W. T. Leung, Y. N. Hong, S. J. Chen, E. G. Zhao, J. W. Y. Lam and B. Z. Tang, J. Am. Chem. Soc., 2013, 135, 62-65.

16 Y. Y. Yuan, R. T. K. Kwok, B. Z. Tang and B. Liu, J. Am. Chem. Soc., 2014, 136, 2546-2554.

17 A. Reisch and A. S. Klymchenko, Small, 2016, 15, 1968-1992. 18 H. Naito, Y. Morisaki and Y. Chujo, Angew. Chem., Int. Ed., 2015, 54, 5084-5087.

19 D. S. Ma, A. A. Jaye, K. L. Ronayne, J. Nappa, S. R. Meech and P. J. Tonge, J. Am. Chem. Soc., 2008, 130, 1227-1235.

20 S. R. Meech, Chem. Soc. Rev., 2009, 38, 2922-2934.
21 A. Baldridge, S. R. Samanta, N. Jayaraj, V. Ramamurthy and L. M. Tolbert, J. Am. Chem. Soc., 2010, 132, 1498-1499.

22 N. Y. A. Baffour-Awuah and M. Zimmer, Chem. Phys., 2004, 303, 7-11.

23 J. S. Yang, G. J. Huang, Y. H. Liu and S. M. Peng, Chem. Commun., 2008, 1344-1346.

24 Y. O. Jung, J. H. Lee, J. Kim, M. Schmidt, K. Moffat, V. Srajer and H. Ihee, Nat. Chem., 2013, 5, 212-220.

25 V. S. Padalkar and S. Seki, Chem. Soc. Rev., 2016, 45, 169-202.

26 K. Benelhadj, J. Massue, P. Retailleau, G. Ulrich and R. Ziessel, Org. Lett., 2013, 15, 2918-2921.

27 K. Furukawa, N. Yamamoto, T. Nakabayashi, N. Ohta, K. Amimoto and H. Sekiya, Chem. Phys. Lett., 2012, 45, 539-540.

28 H. P. Deng and X. Y. Zhu, Materials Chemistry Frontiers, 2016, DOI: $10.1039 / \mathrm{c} 6 q \mathrm{~m} 00148 \mathrm{c}$.

29 H. P. Deng, Y. Su, M. X. Hu, X. Jin, L. He, Y. Pang, R. J. Dong and X. Y. Zhu, Macromolecules, 2015, 48, 5969-5979.

30 D. E. Williams, E. A. Dolgopolova, P. J. Pellechia, A. Palukoshka, T. J. Wilson, R. Tan, J. M. Maier, A. B. Greytak, M. D. Smith, J. A. Krause and N. B. Shustova, J. Am. Chem. Soc., 2015, 137, 2223-2226.

31 J. S. Paige, T. N. Duc, W. J. Song and S. R. Jaffrey, Science, 2012, 335, 1194.

32 Q. Zhou, F. C. Wu, M. Wu, Y. Tian and Z. W. Niu, Chem. Commun., 2015, 51, 15122-15124.

33 L. X. Wu and K. Burgess, J. Am. Chem. Soc., 2008, 130, 40894096.

34 Y. H. Hsu, Y. A. Chen, H. W. Tseng, Z. Y. Zhang, J. Y. Shen, W. T. Chuang, T. C. Lin, C. S. Lee, W. Y. Hung, B. C. Hong, S. H. Liu and P. T. Chou, J. Am. Chem. Soc., 2014, 136, 11805-11812.

35 H. P. Deng, C. Y. Yu, L. D. Gong and X. Y. Zhu, J. Phys. Chem. Lett., 2016, 7, 2935-2944.

36 D. Harries, D. C. Rau and V. A. Parsegian, J. Am. Chem. Soc., 2005, 127, 2184-2190.

37 R. N. Dsouza, U. Pischel and W. M. Nau, Chem. Rev., 2011, 111, 7941-7980.

38 X. Z. Yan, F. Wang, B. Zheng and F. H. Huang, Chem. Soc. Rev., 2012, 41, 6042-6065.

39 P. F. Wei, X. Z. Yan and F. H. Huang, Chem. Soc. Rev., 2015, 44, 815-832.

40 R. J. Dong, Y. F. Zhou and X. Y. Zhu, Acc. Chem. Res., 2014, 47, 2006-2016.

41 J. Dong, K. M. Solntsev and L. M. Tolbert, J. Am. Chem. Soc., 2009, 131, 662-670.

42 H. P. Deng, Q. Zhu, D. L. Wang, C. L. Tu, B. S. Zhu and X. Y. Zhu, Polym. Chem., 2012, 3, 1975-1977.

43 G.-J. Huang, J.-H. Ho, C. Prabhakar, Y.-H. Liu, S.-M. Peng and J.-S. Yang, Org. Lett., 2012, 14, 5034-5037.

44 R. H. Friend, R. W. Gymer, A. B. Holms, J. H. Burroughes, R. N. Marks, C. Taliani, D. D. C. Bradley, D. A. Dos Santos, J. L. Brédas, M. Lögdlund and W. R. Salaneck, Nature, 1999, 397, 121-128.

45 L. M. Tolbert, A. Baldridge, J. Kowalik and K. M. Solntsev, J. Chem. Res., 2012, 45, 171-181. 
46 J. S. Park, J. N. Wilson, K. I. Hardcastle, U. H. F. Bunz and M. Srinivasarao, J. Am. Chem. Soc., 2006, 128, 7714-7715.

47 T. Aida, E. W. Meijer and S. I. Stupp, Science, 2012, 335, 813817.
48 A. Harada, Y. Takashima and H. Yamaguchi, Chem. Soc. Rev., 2009, 38, 875-882.

49 S. S. Babu, V. K. Praveen and A. Ajayaghosh, Chem. Rev., 2014, 114, 1973-2129. 